\title{
1 Reference Values of Impulse Oscillometry (IOS) for Healthy Indian Adults
}

2

3 Running title: Indian prediction equation of IOS

4

6

7

8

9

10 Usmani, MBBS, PhD, FRCP ${ }^{10}$ London, UK

Word Count: 1152 (excluding Tables and Table Legends)

Number of Tables: 1

Number of References: 13

Subhabrata Moitra, $\mathrm{PhD}^{1,2,3}$, Saibal Moitra, MD, $\mathrm{PhD}^{4,5}$, Atanu K. Ghosh, $\mathrm{MSc}^{6}$, Soumya Sengupta, MD, $\mathrm{DNB}^{4}$, Prasanta K Das, BSc ${ }^{4,5}$, Aratrika Das, $\mathrm{MD}^{7}$, Ritabrata Mitra, $\mathrm{MD}^{8}$, Nicola Murgia, $\mathrm{MD}^{9}$, Omar S.

${ }^{1}$ ISGlobal, ${ }^{2}$ CIBER Epidemiologia y Salud Publica (CIBERSP) and ${ }^{3}$ Universitat Pompeu Fabra (UPF), Barcelona, Spain; ${ }^{4}$ Division of Pulmonary Medicine, Charnock Hospital, Kolkata, India; ${ }^{5}$ Department of Pneumology, Allergy \& Asthma Research Centre, Kolkata, India; ${ }^{5}$ Department of Statistics, Presidency University, Kolkata, India; ${ }^{7}$ Department of Respiratory Medicine, Rabindranath Tagore International Institute of Cardiac Sciences, Kolkata, India; ${ }^{8}$ Department of Pulmonary Medicine, Institute of Post Graduate Medical Education \& Research and SSKM Hospital, Kolkata, India; ${ }^{9}$ Department of Medicine, University of Perugia, Perugia, Italy; ${ }^{10}$ National Heart and Lung Institute, Imperial College London,

Correspondence to: Subhabrata Moitra, ISGlobal, PRBB, Doctor Aiguader 88, Barcelona-08003, Spain. Tel: +34-631813559. Email: subhabrata2207@gmail.com

Keywords: Impedance; resistance; reactance; prediction model; small airways 
To the Editor, Impulse oscillometry (IOS) is gaining position within clinical lung function laboratories globally for its effort-independency allowing paediatric, elderly and differently abled patients to breathe at tidal volumes, without necessitating forced effort-dependent respiratory manoeuvres. ${ }^{1}$ IOS indices of resistance $(R)$, reactance $(X)$ and impedance $(Z)$ provide a comprehensive assessment of the functional status of the airways, particularly the small airways, which is not achieved by conventional lung function testing. ${ }^{1}$

India comprises $18 \%$ of the global population and with 93.2 million patients suffering from asthma and chronic obstructive pulmonary disease (COPD), India contributes to $32 \%$ of the global disability-adjusted life years (DALYs) in chronic respiratory diseases. ${ }^{2}$ The aetiology and disease manifestations in patients with asthma and COPD are different than those observed in Caucasian populations due to several non-classical exposures such as biomass fuel, frequent childhood respiratory illnesses, under-nutrition, and industrial/occupational exposures. ${ }^{2}$ IOS could provide muchneeded diagnostic support to Indian clinicians to overcome cases of misdiagnosis.

Current reference models for IOS for adults are limited, and with large heterogeneity in terms of model construction. Moreover, due to ethnic and physiological variations between Indians and other population, those equations do not fit well for Indians. Therefore, we undertook to develop reference equations of the clinically important IOS indices for Indian adults.

Based on an a priori evidence of the standard deviation of airway resistance values at $5 \mathrm{~Hz}\left(\mathrm{R}_{5 \mathrm{~Hz}}\right)$ of $0.07 \mathrm{kPaL}^{-1} \mathrm{Sec}^{-1}$ in healthy Indians, ${ }^{3}$ with a precision of $5 \%$, an alpha risk of 0.05 , and an anticipated non-cooperation rate of $15 \%$, we estimated a total sample size of 202 (101 for each gender). We recruited non-smoking healthy volunteers aged between 18 and 88 years with no clinical history of asthma, COPD, emphysema, allergic rhinitis, respiratory tuberculosis, respiratory infections within four weeks of testing, chest deformity (as observed by chest x-ray); cardiovascular disease; obesity (body mass index $\left.>30 \mathrm{~kg} / \mathrm{m}^{2}\right)$, hospitalization in the last 6 months, pregnancy, or concomitant drug therapy affecting muscarinic and adrenergic receptors. We also excluded those non-smokers who reported exposure to biomass fuel or vapour, dust, gas and fume (VGDF) at work. The study was ethically approved by the Clinical Research Ethics Committee of the Allergy \& Asthma Research Centre, Kolkata (CREC-AARC) and all the participants provided signed informed consent. 
Spirometry and IOS were performed in all participants using a Jaeger MasterScreen ${ }^{\mathrm{TM}}$ PFT system (Jaeger Co, Wurzburg, Germany) equipped for both tests. Spirometry was performed according to American Thoracic Society/European Respiratory Society (ATS/ERS) guidelines. ${ }^{4}$ Forced vital capacity $(F V C)$, forced expiratory volume in 1 second $\left(F E V_{1}\right)$, and $F E V_{1} / F V C$ ratio were measured using established Indian reference equations, ${ }^{5}$ coherent with ATS/ERS criteria for acceptability and repeatability. ${ }^{6}$

IOS was undertaken according to the ATS/ERS statement. ${ }^{6}$ Airway impedance (Z) between $5 \mathrm{~Hz}$ and $20 \mathrm{~Hz}$ frequencies was measured and at least three successive efforts were recorded and quality inspected by at least two clinicians with substantial subject expertise. We reported respiratory impedance at $5 \mathrm{~Hz}(\mathrm{Zrs})$, resistance $(\mathrm{Rrs})$ at $5 \mathrm{~Hz}$ and $20 \mathrm{~Hz}\left(\mathrm{R}_{5}, \mathrm{R}_{20}\right)$, reactance $(\mathrm{Xrs})$ at $5 \mathrm{~Hz}$, resonant frequency (Fres), integrated area of low-frequency reactance $(A X)$, and the absolute difference of $R_{5}$ and $R_{20}\left(R_{5-20}\right)$.

We tested the linear relationships between each of the IOS indices and age, height and weight using generalized additive models (GAM), respectively, taking natural or natural-logarithmic transformations of both the IOS and principal factors, age, height and weight. Based on GAM results, we created different sets of linear regression models for each of the IOS indices taking their natural-logarithmic transformation. We also created additional models using quantile regression with quadratic terms of age, height and weight; but due to the best fit, only the linear models were retained. Heteroskedasticity and goodness of fit of the models were tested using $k$-fold cross-validation $(k=5)$, root mean square error (RMSE) of the residuals, and Akaike's information criteria (AIC). Collinearity between the explanatory variables was measured using variance inflation factor (VIF). All analyses were performed in STATA v15.1 (StataCorp, College St. TX, USA).

After excluding 9 males and 2 females for non-reproducible spirometry, suspected air-leaks during oscillometry, and non-tidal breathing patterns at rest, we incorporated data on 92 males (mean age $45 \pm 18$ years) and 99 females (mean age $41 \pm 17$ years). All participants were non-obese (mean body mass index $23.5 \pm 4.5 \mathrm{~kg} / \mathrm{m}^{2}$ ) and had normal spirometry (mean $\mathrm{FEV}_{1} \%$ predicted $=93.4 \pm 19.1$ and mean $\left.F E V_{1} / F V C=80.3 \pm 9.5\right)$. In case of IOS, compared to males, females had consistently higher overall impedance $\left(\mathrm{Z}_{5}\right)$ [median (IQR) $0.46(0.35,0.57) \quad$ vs. $0.63(0.55,0.80) \mathrm{kPa} / \mathrm{L} / \mathrm{sec}$ ]. Resistance 
90

91

92

93

94

95

96

97

98

99

100

101

102

103

104

105

106

107

108

109

110

111

112

113

114

115

116

117

118

119

$\left(R_{5}, R_{20}\right.$, and $\left.R_{5-20}\right)$ and reactance $\left(X_{5}\right)$ values were consistently higher among females than their male counterparts. (data not shown).

Gender-specific reference models of the commonly used IOS indices are presented in Table 1. We found weight had the most significant influence on the models while height had the lowest, in both genders. All IOS indices achieved high goodness of fit values as measured by adjusted $\mathrm{R}^{2}$ and RMSE, except $\mathrm{AX}$ for males. No collinearity between the explanatory variables was observed $(\mathrm{VIF}<2)$ in any of the models.

In this study, we observed all oscillometry resistance values were higher among females, which is consistent with other studies, ${ }^{7,8}$ however, unlike other studies, we found higher overall reactance (more negative $X_{5}$ ) among females. ${ }^{7,8}$ One plausible explanation of this alternative finding could be because of the fact that unlike the Europeans, Indian females have higher BMI than their male counterparts, ${ }^{9}$ and as higher BMI reduces airway elastance,${ }^{10}$ Indian females are likely to have higher (more negative) reactance values than the males.

Despite the increasing use of IOS in clinical practice, population-wise reference equations for the adults are still lacking except for only a handful number of reference models for the Caucasian, ${ }^{7,8}$ Australian, ${ }^{11}$ and Japanese populations. ${ }^{12}$ Our prediction equations differ significantly from both Caucasian, Australian and Japanese models (data not shown), however, are more accurate for Indian population. The utility of IOS is fast gaining acceptability for accurate clinical diagnosis, and because of the availability of low-cost and portable IOS instruments, its use has increased significantly among Indian clinicians over the last few years. Therefore, developing reference equations for the Indian population has now become important and for the first time, we present predictive models for the clinically relevant IOS indices in an adult Indian population aged between 18 and 88 years which would boost up the clinicians to use IOS more frequently and help estimate the degree of airway obstruction more precisely.

One of the major strengths of our equations is that our model building approach consisted of a series of methods that were tested for 1 ) nature of relationship (linear vs. nonlinear) between the IOS indices and the explanatory variables, 2) heteroskedasticity, 3) goodness of fit, and 4) cross-validation. Moreover, we tested the collinearity between the explanatory variables (using VIF), that may often lead of inaccurate estimation of the effects. ${ }^{13}$ However, one of the limitations of this study is that we did not 
have a cohort for external validation. Therefore, large epidemiological studies are a next-step to confirm the robustness of our models.

FUNDING AND ACKNOWLEDGEMENT: None

CONFLICT OF INTEREST: SUM reports Young Scientist Sponsorship and Long-Term Fellowship from European Respiratory Society, and editorial fee from Lancet Respiratory Medicine, outside the submitted work. SM is in the Board of Directors of NC Das Immunomedicare Pvt. Ltd., Kolkata, has received fees from AstraZeneca, Lupin and Boehringer Ingelheim and non-financial support from GlaxoSmithKline (GSK) outside submitted work. NM reports non-financial support from GSK, personal fees and non-financial support from CHIESI, personal fees and non-financial support from MENARINI, personal fees and non-financial support from AstraZeneca, non-financial support from ALK-ABELLO, outside the submitted work. Other authors do not report any conflict of interest.

\section{REFERENCES}

1. McNulty W, Usmani OS. Techniques of assessing small airways dysfunction. Eur Clin Respir J 2014; 1 .

2. India State-Level Disease Burden Initiative CRD Collaborators. The burden of chronic respiratory diseases and their heterogeneity across the states of India: the Global Burden of Disease Study 1990-2016. Lancet Glob Health 2018; 6(12): e1363-e1374.

3. Rafie S, Moitra S, Brashier B. Association between the Serum Metabolic Profile and Lung Function in Chronic Obstructive Pulmonary Disease. Turk Thorac J 2018; 19: 13-18

4. Miller MR, Hankinson J, Brusasco V, et al. Standardisation of spirometry. Eur Respir J 2005; 26(2): 319-338.

5. Dasgupta A, Ghoshal AG, Mukhopadhyay A, et al. Reference equation for spirometry interpretation for Eastern India. Lung India 2015; 32: 34-39.

6. King GG, Bates J, Berger KI, et al. Technical Standards for Respiratory Oscillometry. Eur Respir J 2019. pii: 1900753. 
7. Pasker HG, Schepers R, Clement J, et al. Total respiratory impedance measured by means of the forced oscillation technique in subjects with and without respiratory complaints. Eur Respir $\mathrm{J}$ 1996; 9: 131-139.

8. Vogel J, Smidt U. Impulse Oscillometry. Analysis of lung mechanics in general practice and clinic, epidemiological and experimental research. Frankfurt (Germany): PMI-Verlagsgruppe; 1994.

9. Rush EC, Freitas I, Plank LD. Body size, body composition and fat distribution: comparative analysis of European, Maori, Pacific Island and Asian Indian adults. Br J Nutr 2009; 102(4): 632641.

10. van de Kant KD, Paredi $P$, Meah $S$, et al. The effect of body weight on distal airway function and airway inflammation. Obes Res Clin Pract 2016; 10(5): 564-573.

11. Newbury W, Crockett A, Newbury J. A pilot study to evaluate Australian predictive equations for the impulse oscillometry system. Respirology 2008; 13: 1070-1075.

12. Shiota S, Katoh M, Fujii M, et al. Predictive equations and the reliability of the impulse oscillatory system in Japanese adult subjects. Respirology 2005; 10: 310-315.

13. Narchi H, AlBlooshi A. Prediction equations of forced oscillation technique: the insidious role of collinearity. Respir Res 2018; 19: 48

7

9

(1)

182

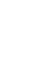

7

88

189


194 Table 1: Gender-specific prediction models for IOS indices

\begin{tabular}{|c|c|c|c|c|}
\hline Parameters & Models & Adjusted $\mathbf{R}^{2}$ & RMSE & Mean VIF \\
\hline \multicolumn{5}{|l|}{ Males } \\
\hline $\ln \mathrm{R}_{5}$ & $-0.30+0.003($ Age $)+0.01($ Weight $)-0.83($ Height $)$ & 0.04 & 0.40 & 1.48 \\
\hline $\ln R_{20}$ & $-0.14-0.001($ Age $)+0.01($ Weight $)-0.99($ Height $)$ & 0.10 & 0.26 & 1.48 \\
\hline $\ln R_{5-20}$ & $-4.05+0.02($ Age $)+0.004($ Weight $)+0.68($ Height $)$ & 0.02 & 1.13 & 1.47 \\
\hline $\ln Z_{5}$ & $0.79+0.008($ Age $)+0.008($ Weight $)-1.42($ Height $)$ & 0.09 & 0.43 & 1.25 \\
\hline$X_{5}$ & $-0.23-0.002($ Age $)-0.002($ Weight $)+0.15($ Height $)$ & 0.01 & 0.23 & 1.48 \\
\hline $\ln A X$ & $-0.20+1.24($ lnAge $)+0.01($ Weight $)-2.98($ Height $)$ & 0.20 & 1.02 & 1.25 \\
\hline InFres & $2.44+0.39(\ln A g e)+0.001($ Weight $)-0.55($ Height $)$ & 0.15 & 0.34 & 1.25 \\
\hline \multicolumn{5}{|l|}{ Females } \\
\hline $\ln R_{5}$ & $0.003+0.004($ Age $)+0.007($ Weight $)-0.66($ Height $)$ & 0.08 & 0.33 & 1.07 \\
\hline $\ln R_{20}$ & $0.164+0.0003($ Age $)+0.007($ Weight $)-0.92($ Height $)$ & 0.12 & 0.22 & 1.07 \\
\hline $\ln R_{5-20}$ & $-3.35+0.007($ Age $)+0.01($ Weight $)+0.68($ Height $)$ & 0.02 & 0.86 & 1.06 \\
\hline $\ln Z_{5}$ & $-0.68+0.27(\ln A g e)+0.003($ Weight $)-0.53($ Height $)$ & 0.08 & 0.32 & 1.06 \\
\hline$X_{5}$ & $-0.60-0.004($ Age $)-0.001($ Weight $)+0.37($ Height $)$ & 0.16 & 0.16 & 1.07 \\
\hline $\ln A X$ & $-2.33+0.76($ lnAge $)+0.004($ Weight $)-0.004($ Height $)$ & 0.08 & 0.80 & 1.06 \\
\hline InFres & $1.19+0.27($ lnAge $)+0.0002($ Weight $)+0.68($ Height $)$ & 0.07 & 0.31 & 1.06 \\
\hline
\end{tabular}

195 Models built using linear regression analysis taking age (in years), weight (in $\mathrm{kg}$ ) and height (in meters) as 196 main explanatory variables. In: natural logarithm. VIF: variance inflation factor. For other abbreviations, see 197 the text. 